\title{
Penggunaan Metode Simple Addtive Weighting (SAW) Untuk Menetukan Calon Penerima Beasiswa
}

\author{
Supriyati ${ }^{1)}$, Kusrini $^{2)}$, Emha Taufiq Luthfi ${ }^{3)}$ \\ Magister Teknik Informatika Universitas Amikom Yogyakarta \\ J1. Ringroad Utara, Condong Catur, Sleman, Yogyakarta 55283 Indonesia \\ ${ }^{1}$ supriyati.13@students.amikom.ac.id, ${ }^{2}$ kusrini@amikom.ac.id , ${ }^{3}$ emhataufiqluthfi@ amikom.ac.id
}

\begin{abstract}
Abstrak
Pendidikan yang semakin tinggi akan membuka jalan seseorang menuju masa depan yang lebih baik. Bantuan pendidikan berupa beasiswa dari sekolah yang diberikan kepada siswa mampu menjadi motivasi tersendiri bagi siswa yang berprestasi. Data yang diolah pada penelitian ini diambil dari Smk Syubbanul Wathon Tegalrejo Magelang sebagai data input. Kriteria-kriteria yang diolah antara lain, data nilai rata-rata rapot, penghasilan orang tua, dan jumlah tanggungan orang tua dengan data alternatif (kandidat) 20 siswa. Penelitian ini bertujuan untuk membantu sekolah dalam menentukan calon penerima beasiswa dengan menggunakan metode Simple Additive Weighting (SAW). Hasil penelitian ini mampu menunjukkan bahwa alternatif yang memiliki nilai preferensi yang tertinggi dapat dijadikan prooritas sebagai calon penerima beasiswa.
\end{abstract}

Kata kunci:SPK, Pendidikan, beasiswa, kriteria, SAW

\section{PENDAHULUAN}

Beasiswa merupakan bentuk penghargaan yang diberikan kepada individu agar dapat melanjutkan pendidikan ke jenjang yang lebih tinggi[1]. Sehingga dengan adanya beasiswa dapat menciptakan semangat bagi peserta didik untuk lebih berprestasi dan meraih cita-citanya.

Penelitian-penelitian yang terdahulu berkaitan dengan calon penerima beasiswa ada penelitian pertama berjudul Metode Simple Additive Weighting (SAW) untuk Penerimaan Beasiswa PPA (Peningkatan Prestasi Akademik) pada Universitas Teknologi Yogyakarta yang dilakukan Hafis Al Aziz dan Joko Sutopo (2018) menjelaskan bahwa kriteria prestasi akademik, IPK, dan penghasilan orang tua memiliki bobot yang tinggi masing-masing sebesar 18\%, $17 \%$ dan $16 \%$ dari total 10 kriteria yang dimasukkan sehingga mempengaruhi hasil prioritas calon penerima beasiswa.

Penelitian kedua yang dilakukan oleh Muqorobin, dkk (2019) yang berjudul Sistem Pendukung Keputusan Penerima Beasiswa dengan Metode SAW membuktikan bahwa penggunaan sistem pendukung keputusan metode SAW valid antara hitungan manual dengan hitungan sistem diperoleh hasil yang sama.
Banyaknya calon penerima beasiswa maka pihak sekolah harus selektif dalam menentukan siapa yang layak untuk mendapatkan beasiswa tersebut. Ada beberapa kriteria yang dipertimbangkan dalam penyeleksian calon penerima beasiswa, antara lain nilai rapot, penghasilan orang tua, jumlah tanggungan orang tua, dan juga bisa ditambahkan kriteria-kriteria lain yang dibutuhkan. Penggunaan metode yang masih manual menyebabkan kurang efektif dalam mengambil keputusan, waktu yang dibutuhkan relatif lebih lama, dan juga cenderung bersifat subjektif.

Oleh karena itu, peneliti akan menggunakan metode Simple Additive Weighting (SAW) untuk membantu pemangku kebijakan sekolah dalam menyelesaikan masalah siapa yang layak mendapatkan beasiswa. Metode ini mampu menghitung setiap atribut pada alternatif yang dimasukkan. Dan dengan bobot yang diberikan akan menyeleksi alternatif yang terbaik.

\section{METODE PENELITIAN}

Peneliti melakukan beberapa tahapan dalam proses penelitian, antara lain:

\section{a. Teknik Pengumpulan Data}

Pengumpulan data yang dilakukan pada penelitian ini, seperti: 
1) Wawancara

Peneliti mengajukan pertanyaan lisan kepada Kepala Sekolah berkaitan dengan kebijakan besaran beasiswa dan periode pemberian beasiswa, juga bendahara sekolah berkaitan dengan alur keputusan uang beasiswa sampai kepada penerima beasiswa.

2) Observasi

Peneliti melakukan pengamatan langsung pada lingkup penelitian yaitu SMK Syubbanul Wathon Tegakrejo Magelang terkait dengan data-data yang diperlukan, yaitu data siswa, data orang tua, dan data nilai.

3) Kuesioner

Peneliti mendapatkan data berapa penghasilan orang tua dan berapa jumlah tanggungan orang tua dari koresponden (siswa yang diteliti) yang mengisi kuesioner.

\section{b. Teknik Analisis Data}

Pada penelitian ini pengolahan data menggunakan metode Simple Addtive Weighting (SAW). Metode ini juga dikenal dengan metode penjumlahan terbobot. Metode ini masing-masing atribut diberi bobot dan jumlah semua bobot adalah 1 . Penjumlahan dari keseluruhan atribut akan dikalikan dengan nilai setiap alternatif[3]. Nilai dari setiap alternatif dirumuskan sebagai berikut:

$$
V i=\sum_{j=1}^{M} W_{j} \times r_{i j}
$$

Langkah analisis data dengan menggunakan SAW dalam menentukan calon penerima beasiswa, sebagai berikut:

1. Tentukan alternatif dan kriteria dari data yang diteliti.

2. Tentukan bobot dari setiap kriteria.

3. Tentukan apakah kriteria yang digunakan itu termasuk benefit atau cost.

4. Hitung normalisasinya

$$
\boldsymbol{r}_{\boldsymbol{i j}} \begin{cases}\frac{\boldsymbol{x}_{i j}}{\boldsymbol{\boldsymbol { m a x } _ { ( x _ { i j } ) }}} & , \text { Jika } \mathrm{j} \text { adalah atribut benefit } \\ \frac{\boldsymbol{\operatorname { m i n }}_{\left(x_{i j}\right)}}{\boldsymbol{x}_{i j}} & , \text { Jika } \mathrm{j} \text { adalah atribut cost }\end{cases}
$$

5. Jumlahkan setiap bobot kriteria W menggunakan rumus (1) untuk mendapat $\mathrm{V}_{\mathrm{i}}$ yang mana hasil tersebut merupakan nilai akhir normalisasi.
6. Urutkan hasil akhir normalisasi dari yang tertingggi ke yang terendah.

Langkah-langkah yang dilakukan dapat digambarkan sebagai berikut:

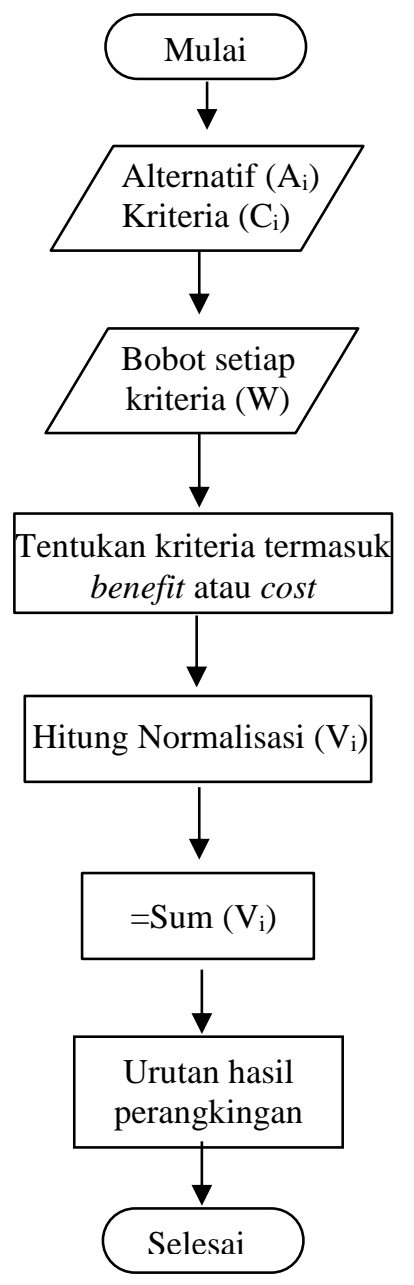

Gambar 1. Flowchart metode SAW

\section{TINJAUAN PUSTAKA}

\section{a. Sistem Pendukung Keputusan}

Konsep sistem pendukung keputusan merupakan sistem yang mengubah data menjadi informasi yang digunakan untuk membantu pengguna dalam mengambil keputusan dalam memecahkan masalah. Konsep ini dikenalkan oleh Michael S. Scoot pada tahun 1970-an dengan istilah Management Decision System (Iwan \& Lirien, 2012). Sistem Pendukung Keputusan (SPK) adalah penerapan dari Multi Attribute Decision Making (MADM). Metode MADM difokuskan pada bagaimana pengambil keputusan menetapkan bobot nilai kriteria berdasarkan referensi mereka. 


\section{b. Metode Simple Additive Weighting (SAW)}

Metode Simple Additive Weighting (SAW) adalah metode yang paling sederhana dan terbanyak digunakan (Kittur dkk., 2015). Metode Simple Additive Weighting (SAW) juga dikenal dengan metode penjumlahan tertimbang. Konsep dasar dari metode SAW adalah untuk menemukan jumlah peringkat kinerja tertimbang pada setiap alternatif pada semua atribut (Siswanto dkk., 2017). Metode ini memudahkan pemilihan faktor pembobotan atau atribut (Muddineni dkk., 2017). Di metode SAW, masing-masing atribut diberi bobot dan jumlah semua bobot harus 1 (Kittur dkk., 2015). Setiap alternatif dinilai berkaitan dengan setiap atribut.

\section{HASIL DAN PEMBAHASAN}

Penelitian ini diimplementasikan perhitungan metode SAW menggunakan Ms. Excel. Data uji berasal dari data siswa kelas XI SMK Syubbanul Wathon Tegalrejo Magelang yang menjadi alternatif (kandidat) calon penerima beasiswa.

\section{a. Perhitungan dengan menggunakan SAW}

Langkah awal yang dilakukan pada tahap ini adalah menentukan alternatif yaitu nama siswa yang akan menjadi calon peneriam beasiswa. Selanjutnya menentukan kriteria yang dimiliki oleh alternatif.

Tabel 1. Alternatif

\begin{tabular}{cl}
\hline No & \multicolumn{1}{c}{ Nama (Ai) } \\
\hline 1 & Achmad Manarul Hidayat \\
2 & Afan Yoga Dimasa'ied \\
3 & Afif Fiaaliy \\
4 & Afwan Afafan Adha Muhammad \\
5 & Ahmad Aldiyan Syah \\
6 & Ahmad Fauzan Nurul Huda \\
7 & Akhmad Raikhan Tsani \\
8 & Aldi Liani \\
9 & Aldian Chindra Aji \\
10 & A'raaf Oktaviolla Lintang Setia \\
11 & Bouna Husain \\
12 & Bravera Putra Abhinaya \\
13 & Eko Purnomo Adi \\
14 & Farid Panjasela Ramadhani \\
15 & Ibnu Ngatoilah \\
16 & Ibrahim Ali Abel \\
17 & Ilmi Muhammad Adib
\end{tabular}

18 In'am Zainul Muttaqin

19 Achmad Manarul Hidayat

20 Afan Yoga Dimasa'ied

Tabel 2. Kriteria

\begin{tabular}{clc}
\hline No & \multicolumn{1}{c}{ Kriteria (Ci) } & Simbol \\
\hline 1 & Nilai Rata-rata Rapot & C1 \\
2 & Penghasilan Orang Tua & C2 \\
3 & Jml Tanggungan & C3 \\
\hline
\end{tabular}

Tabel 3. Prosentase Bobot Kriteria

\begin{tabular}{clc}
\hline No & \multicolumn{1}{c}{ Kriteria (Ci) } & Bobot(W) \\
\hline 1 & Nilai Rata-rata Rapot & 0,4 \\
2 & Penghasilan Orang Tua & 0,3 \\
3 & Jml Tanggungan & 0,3 \\
\hline
\end{tabular}

Pada tabel kriteria di atas dapat dilanjutkan dengan menetukan apakah kriteria-kriteria tersebut termasuk benefit atau cost.

Tabel 4. Benefit/Cost

\begin{tabular}{clc}
\hline No & \multicolumn{1}{c}{ Kriteria (ci) } & Benefit/Cost \\
\hline 1 & Nilai Rata-rata & Benefit \\
& Rapot & \\
2 & $\begin{array}{l}\text { Penghasilan Orang } \\
\text { Tua }\end{array}$ & Cost \\
3 & Jml Tanggungan & Benefit \\
\hline
\end{tabular}

Langkah selanjutnya yang dilakukan adalah menghitung normalisasi yaitu nilai dari setiap kriteria dikalikan dengan prosentase bobot yang telah ditetapkan seperti pada tabel 3.

Tabel 5. Data Alternatif da Kriteria Calon Penerima Beasiswa

\begin{tabular}{lccl}
\hline \multirow{2}{*}{ Alternatif } & \multicolumn{3}{c}{ Kriteria } \\
\cline { 2 - 4 } & C1 & C2 & C3 \\
\hline Achmad & 72 & 750.000 & 2 \\
$\begin{array}{l}\text { Manarul } \\
\text { Hidayat }\end{array}$ & & & \\
$\begin{array}{l}\text { Afan Yoga } \\
\text { Dimasa'ied }\end{array}$ & 80 & 1.000 .000 & 1 \\
$\begin{array}{l}\text { Afif Fiaaliy } \\
\text { Afwan Afafan }\end{array}$ & 76 & 1.500 .000 & 2 \\
$\begin{array}{l}\text { Adha } \\
\text { Muhammad }\end{array}$ & & 1.000 .000 & 3 \\
$\begin{array}{l}\text { Ahmad } \\
\text { Aldiyan Syah } \\
\text { Ahmad Fauzan }\end{array}$ & 60 & 750.000 & 3 \\
Nurul Huda & & 1.500 .000 & 1 \\
\end{tabular}




\begin{tabular}{lccc} 
Akhmad & 84 & 3.500 .000 & 3 \\
Raikhan Tsani & & & \\
Aldi Liani & 79 & 1.000 .000 & 2 \\
$\begin{array}{l}\text { Aldian Chindra } \\
\text { Aji }\end{array}$ & 83 & 3.500 .000 & 3 \\
$\begin{array}{l}\text { A'raaf } \\
\text { Oktaviolla }\end{array}$ & 80 & 750.000 & 2 \\
$\begin{array}{l}\text { Lintang Setia } \\
\text { Bouna Husain }\end{array}$ & 70 & 1.500 .000 & 3 \\
$\begin{array}{l}\text { Bravera Putra } \\
\text { Abhinaya }\end{array}$ & 75 & 3.500 .000 & 3 \\
$\begin{array}{l}\text { Eko Purnomo } \\
\text { Adi }\end{array}$ & 62 & 1.500 .000 & 2 \\
$\begin{array}{l}\text { Farid Panjasela } \\
\text { Ramadhani }\end{array}$ & 86 & 1.500 .000 & 2 \\
$\begin{array}{l}\text { Ibnu Ngatoilah } \\
\text { Ibrahim Ali }\end{array}$ & 87 & 750.000 & 2 \\
$\begin{array}{l}\text { Abel } \\
\text { Ilmi }\end{array}$ & 82 & 1.500 .000 & 2 \\
$\begin{array}{l}\text { Muhammad } \\
\text { Adib }\end{array}$ & & 1.500 .000 & 2 \\
$\begin{array}{l}\text { In'am Zainul } \\
\text { Muttaqin }\end{array}$ & 80 & 3.500 .000 & 3 \\
$\begin{array}{l}\text { Kandayas } \\
\text { Nouval } \\
\text { Maghfoor }\end{array}$ & 75 & 5.000 .000 & 2 \\
$\begin{array}{l}\text { M Agung } \\
\text { Haidar }\end{array}$ & & & \\
\hline & 89 & 750.000 & 4 \\
\hline
\end{tabular}

Tabel 6. Data Hasil Normalisasi

\begin{tabular}{lcccc}
\hline \multirow{1}{*}{ Alternatif } & $\mathbf{C 1}$ & $\mathbf{C 2}$ & $\mathbf{C 3}$ & $\sum_{n}$ \\
\cline { 2 - 4 } & $\mathbf{0 , 4}$ & $\mathbf{0 , 3}$ & $\mathbf{0 , 3}$ & $\mathbf{V i}$ \\
\hline $\begin{array}{l}\text { Achmad Manarul } \\
\text { Hidayat }\end{array}$ & 0,80 & 1,00 & 0,5 & 0,77 \\
$\begin{array}{l}\text { Afan Yoga } \\
\text { Dimasa'ied }\end{array}$ & 0,89 & 0,75 & 0,25 & 0,66 \\
$\begin{array}{l}\text { Afif Fiaaliy } \\
\text { Afwan Afafan } \\
\text { Adha }\end{array}$ & 0,84 & 0,50 & 0,5 & 0,64 \\
$\begin{array}{l}\text { Muhammad } \\
\text { Ahmad Aldiyan }\end{array}$ & 0,91 & 0,75 & 0,75 & 0,81 \\
$\begin{array}{l}\text { Syah } \\
\text { Ahmad Fauzan }\end{array}$ & 1,00 & 1,00 & 0,75 & 0,93 \\
$\begin{array}{l}\text { Nurul Huda } \\
\text { Akhmad Raikhan }\end{array}$ & 0,72 & 0,50 & 0,25 & 0,51 \\
$\begin{array}{l}\text { Tsani } \\
\begin{array}{l}\text { Aldi Liani } \\
\text { Aldian Chindra }\end{array}\end{array}$ & 0,93 & 0,21 & 0,75 & 0,66 \\
$\begin{array}{l}\text { Aji } \\
\text { A'raaf Oktaviolla }\end{array}$ & 0,92 & 0,75 & 0,5 & 0,73 \\
Lintang Setia & 0,89 & 1,00 & 0,75 & 0,66 \\
\hline
\end{tabular}

\begin{tabular}{lcccc}
$\begin{array}{l}\text { Bouna Husain } \\
\text { Bravera Putra } \\
\text { Abhinaya }\end{array}$ & 0,78 & 0,50 & 0,75 & 0,69 \\
$\begin{array}{l}\text { Eko Purnomo } \\
\text { Adi }\end{array}$ & 0,83 & 0,21 & 0,75 & 0,62 \\
$\begin{array}{l}\text { Farid Panjasela } \\
\text { Ramadhani }\end{array}$ & 0,69 & 0,50 & 0,5 & 0,58 \\
$\begin{array}{l}\text { Ibnu Ngatoilah } \\
\text { Ibrahim Ali Abel }\end{array}$ & 0,96 & 0,50 & 0,5 & 0,68 \\
$\begin{array}{l}\text { Ilmi Muhammad } \\
\text { Adib }\end{array}$ & $0,9,00$ & 0,5 & 0,84 \\
$\begin{array}{l}\text { In'am Zainul } \\
\text { Muttaqin }\end{array}$ & 0,89 & 0,50 & 0,5 & 0,63 \\
$\begin{array}{l}\text { Kandayas } \\
\text { Nouval }\end{array}$ & & & 0,75 & 0,64 \\
$\begin{array}{l}\text { Maghfoor } \\
\text { M Agung Haidar }\end{array}$ & 0,83 & 0,15 & 0,5 & 0,53 \\
\hline
\end{tabular}

Tabel 7. Data Peringkat Alternatif

\begin{tabular}{|c|c|c|}
\hline Alternatif & $\sum \mathbf{V i}$ & Peringkat \\
\hline M Agung Haidar & 0,94 & 1 \\
\hline Ahmad Aldiyan Syah & 0,93 & 2 \\
\hline Ibnu Ngatoilah & 0,84 & 3 \\
\hline $\begin{array}{l}\text { Afwan Afafan Adha } \\
\text { Muhammad }\end{array}$ & 0,81 & 4 \\
\hline $\begin{array}{l}\text { A'raaf Oktaviolla } \\
\text { Lintang Setia }\end{array}$ & 0,81 & 5 \\
\hline $\begin{array}{l}\text { Achmad Manarul } \\
\text { Hidayat }\end{array}$ & 0,77 & 6 \\
\hline Aldi Liani & 0,73 & 7 \\
\hline Bouna Husain & 0,69 & 8 \\
\hline $\begin{array}{l}\text { Farid Panjasela } \\
\text { Ramadhani }\end{array}$ & 0,68 & 9 \\
\hline Ilmi Muhammad Adib & 0,66 & 10 \\
\hline $\begin{array}{l}\text { Akhmad Raikhan } \\
\text { Tsani }\end{array}$ & 0,66 & 11 \\
\hline Aldian Chindra Aji & 0,66 & 12 \\
\hline Afan Yoga Dimasa'ied & 0,66 & 13 \\
\hline In'am Zainul Muttaqin & 0,64 & 14 \\
\hline Afif Fiaaliy & 0,64 & 15 \\
\hline Ibrahim Ali Abel & 0,63 & 16 \\
\hline $\begin{array}{l}\text { Bravera Putra } \\
\text { Abhinaya }\end{array}$ & 0,62 & 17 \\
\hline Eko Purnomo Adi & 0,58 & 18 \\
\hline $\begin{array}{l}\text { Kandayas Nouval } \\
\text { Maghfoor }\end{array}$ & 0,53 & 19 \\
\hline $\begin{array}{l}\text { Ahmad Fauzan Nurul } \\
\text { Huda }\end{array}$ & 0,51 & 20 \\
\hline
\end{tabular}




\section{KESIMPULAN DAN SARAN \\ a. Kesimpulan}

Berdasarkan dari pembahasan di atas bahwa metode Simple Additive Weighting (SAW) dapat memecahkan masalah dalam menentukan calon penerima beasiswa yang layak. Calon penerima beasiswa dihitung dari nilai preferensi (Vi) tertinggi dari masingmasing alternatif sehingga nilai $\mathrm{Vi}$ yang tertinggi menjadi prioritas pertama sebagai penerima beasswa.

\section{b. Saran}

Saran untuk lanjutan penelitian berikutnya bisa ditambahkan data kriteria dan jumlah data. Semakin banyak data yang diproses SAW maka akan mempengaruhi hasil nilai preferensi.

\section{REFERENSI}

Anjar Wanto dan Hamonangan Damanik "Analisis Penerapan Sistem Pendukung Keputusan Terhadap Seleksi Penerima Beasiswa BBM (Bantuan Belajar Mahasiswa) Pada Perguruan Tinggi Menggunakan Metode Simple Additive Weighting (SAW) (Studi Kasus : AMIK Tunas Bangsa Pematangsiantar)", Prosiding Seminar Nasional Rekayasa (SNTR) II Volume (2) 25 November 2015 , ISSN : 2407735 .

Candra Surya "Sistem Pendukung Keputusan Rekomendasi Penerima Beasiswa Menggunakan Fuzzy Multi Attribut Decision Making (FMADM) dan Simple Additive Weighting (SAW)", Jurnal Rekayasa Elektrika Vol. 11, pp. 123-156, Agustus 2015.

Khoirun Nisa, Kusrini, dan Sudarmawan yang berjudul "Sistem Pendukung Keputusan Kenaikan Pangkat Karyawan", Jurnal INFORMA Politeknik Indonusa Surakarta, Vol. 4 Nomor 3 Tahun 2018, ISSN: 2442-7942.

Kittur yang berjudul "Optimal generation evaluation using SAW, WP, AHP and PROMETHEE multiCriteria decision making techniques. In Advancements in Power and Energy (TAP Energy)", International Conference on (pp. 304309) IEEE, 2015.
M. Erny. 2008. Winning a Scholarship., 1st ed, Jakarta Selatan: Gagas Media.

Muhammad Alfadin Salim"Sistem Pendukung Keputusan Pemilihan Penerima Bantuan Perbaikan Rumah Menggunakan Metode Simple Additive Wieghting (Saw) Studi Kasus Kelurahan Tambelan Sampit Kota Pontianak", Jurnal SISTEMASI, Volume 7, Nomor 2, Mei 2018 : 120 131.

Muqorobin, A. Aflahah, dan Kusrini "Sistem Pendukung Keputusan Penerimaan Beasiswa dengan Metode SAW", Jurnal Teknologi Informasi, Vol. XIV, pp. 76 - 85, Maret 2019

Tri Susilowati, Suyono, dan Widi Andewi "Decision Support System To Determine Scholarship Recipients At Sman 1 Bangunrejo Using Saw Method", International Journal Information System and Computer Science (IJISCS), pp. 59-66, 2017. 